\title{
PARAMETRIC OPTIMIZATION OF EDM PROCESSES FOR ALUMINUM HYBRID METAL MATRIX COMPOSITE USING GRA-PCA APPROACH
}

\author{
GURPREET SINGH MATHAROU ${ }^{1} \&$ BASANTA KUMAR BHUYAN $^{2}$ \\ ${ }^{1}$ Research Scholar, Department of Automobile Engineering, Manav Rachna International \\ Institute of Research and Studies, Faridabad, Haryana, India \\ ${ }^{2}$ Research Scholar, Department of Mechanical Engineering FET, Manav Rachna International \\ Institute of Research and Studies, Faridabad, Haryana, India
}

\begin{abstract}
This study is an attempt to identify the key input parameters of the Electric Discharge Machining (EDM) process, during machining of Hybrid Metal Matrix Composite (HMMC) prepared through the Stir casting method. A multi optimization tool mix of Taguchi Methodology (T-M), Grey Relational Analysis (GRA), and Principal Component Analysis (PCA) was used to optimize and verify the model. The response on Material Removal Rate (MRR), Electrode Wear Rate (EWR) and Surface Roughness $\left(R_{a}\right)$ was investigated by selecting input parameters comprising of peak current $\left(I_{p}\right)$, Pulse on Time $\left(T_{o n}\right)$, Duty factor $(\tau)$, Spark gap $\left(S_{g}\right)$, Electrode type (ET), Electrode size (ES) using Taguchi L ${ }_{16}$ orthogonal array $(\mathrm{OA})$. The optimized process parameter context using GRAPCA, demonstrates the enhancement of MRR by $172.5 \%$ and reduction in EWR and $R_{a}$ by $64.17 \%, 34.4 \%$ respectively using $I_{p 3} T_{o n 1} T_{3} S_{g 2} E T_{2} E S_{1}$ parameter settings against the initial assumed settings. The maximum contributors amongst all parameters were $T_{\text {on }}$ and $I_{p}(21 \%, 14.31 \%)$, followed by ET (12.4\%), $S_{g}(11.5 \%)$ by using Analysis of Variance (ANOVA).

KEYWORDS: Hybrid Metal Matrix Composite, MRR, EWR, Electric Discharge Machining, GRA, PCA, Optimization, Input Parameters
\end{abstract}

Received: Feb 22, 2020; Accepted: Mar 13, 2020; Published: May 05, 2020; Paper Id.: IJMPERDJUN202034

\section{INTRODUCTION}

With the advent of technology, the industry of today's time requires materials with improved strength and hardness, reduced weight with low densities, etc. Composite materials, to a greater extent, had fulfilled the requirement of today's industries. Aluminum HMMC has got lots of demand for elaborative applications in automobiles, mineral processing industries, aerospace etc. Metal matrix composites has emerged as an advance engineering materials due to their high stiffness, high strength, less density, better resistance against wear and high thermal properties (Nturanabo et al., 2019). To machine such HMMC, Electric discharge machining (EDM) has been preferred over other nonconventional methods. It is a contactless machining process based on the erosive impact of electrical discharges. Due to the electro-thermal nature of the process, a large variety of conductive materials can be machined independent of their hardness and toughness, its contactless nature has resulted in an acceptable level of accuracy and surface texture (Joshi et al., 2019). One of the most popular types, i.e., die-sinking EDM has a provision of creating mirror shape of the electrode on the workpiece. In EDM process, the input variables such as current $\left(\mathrm{I}_{\mathrm{p}}\right)$, gap voltage $(\mathrm{V})$, pulse on time $\left(\mathrm{T}_{\mathrm{on}}\right)$, the pulse of time $\left(\mathrm{T}_{\mathrm{off}}\right)$, spark gap $\left(\mathrm{S}_{\mathrm{g}}\right)$, flushing pressure $(\mathrm{FP})$ duty factor/ cycle $(\tau)$ and lift time $\left(\mathrm{T}_{\mathrm{L}}\right)$ has got more influence on output variables like Material Removal Rate (MRR), electrode wear rate (EWR), surface finish ( $\left.R_{a}\right)$, overcut $\left(\mathrm{O}_{\mathrm{c}}\right)$, undercut $(\mathrm{Uc})$, dimensional deviation (DD), etc. (Sahu et al., 2019) had conducted an experiment with 
Nimonic alloy workpiece with the copper electrode to study the effect of $I_{p}$ and $T_{\text {on }}$ on MRR, EWR, and $R_{a}$. They reported that with the variation of $I_{p}$ and $T_{o n}, M R R$, and EWR increases. (Dikshit et al., 2019) had investigated by an empirical formula the output variables $R_{a}$ and MRR during EDM of Inconel 625 superalloy. They concluded that MRR is influenced mainly by $I_{p}$ and $T_{o n}, R_{a}$ by $T_{o n}$, and then by $T_{\text {off. }}$ (Singh et al., 2019) had investigated the effects of $S_{g}, V, I_{p} \& T_{o n}$ on MRR, EWR and $R_{a}$ using one variable at a time (OVAT) approach on $\mathrm{H} 13$ alloy with $\mathrm{Cu}$ electrode. They reported a significant direct effect of $\mathrm{I}_{\mathrm{p}}$ and $T_{o n}$ on MRR and inverse relation of $I_{p}$ on $R_{a}$ and EWR.(Choudhary et al., 2017) had investigated the influence of $I_{p}, T_{o n}$ and $\mathrm{T}_{\text {off }}$ on MRR and $\mathrm{R}_{\mathrm{a}}$ observed during EDM of Hastelloy C-4 material as per T-M L $\mathrm{L}_{18}$ OA with cryogenic treated and normal electrode. They reported better $\mathrm{R}_{\mathrm{a}}$, using a cryogenic treated electrode. (Ram Prasad et al., 2019) had conducted WireEDM of Ti-6Al-4V (Lead-induced) with $\mathrm{Zn}$ coated brass wire to find out the effects of $\mathrm{I}_{\mathrm{p}}, \mathrm{T}_{\mathrm{on}}, \mathrm{V}$, and $\mathrm{T}_{\text {off }}$ on MRR, $\mathrm{R}_{\mathrm{a}}$, DD in a $\mathrm{L}_{27}$ OA. Analytic Hierarchy Process (AHP) coupled with the technique for order of preference by the similarity of ideal solution (TOPSIS) method has been employed to ascertain the most notable settings of input parameters.(Singh Bains et al., 2018) had performed trials on EDM of Al-SiC composites under magnetic field strength impact using different electrodes $(\mathrm{Cu}, \mathrm{Gr} \& \mathrm{~W})$. They reported that the regularity of the experiment has improved, MRR and $\mathrm{R}_{\mathrm{a}}$ to be significantly affected due to the magnetic field, $\mathrm{I}_{\mathrm{p}}$ apart from $\mathrm{T}_{\mathrm{on}}$. Copper has been reported to be the best to machine Al-SiC composite. (Meshram et al., 2020) had conducted $\mathrm{L}_{18}$ OA based DOE on semi-circular curved $\mathrm{Cu}$ electrode used for EDM on OHNS steel to ascertain the effects of input variables comprising of $\mathrm{I}_{\mathrm{p}}, \mathrm{T}_{\mathrm{on}}$, FP, model validated by use of ANOVA. (Kumar et al., 2018) had attempted EDM of monel 400 material with Copper-TitanumDi-boride $\left(\mathrm{Cu}-\mathrm{TiB}_{2}\right)$ electrode fabricated through the powder metallurgy process. Central rotatable composite design (CCRD) and Response Surface Methodology (RSM) approach have been used to validate the model of input variables ( $\mathrm{TiB}_{2} \% \mathrm{wt}, \mathrm{I}, \mathrm{T}_{\mathrm{on}}$, and $\mathrm{FP}$ ) on MRR and EWR. They suggested that the best settings of input parameters is \%wt of $\mathrm{TiB}_{2}$ to be $16 \%, \mathrm{I}=6 \mathrm{Amp}$, FP of $1 \mathrm{Mpa}$, and $\mathrm{T}_{\text {on }}$ of $35 \mu \mathrm{s}$. (Payal et al., 2019) had conducted EDM on Inconel 825 with input parameters $\mathrm{V}, \mathrm{T}_{\text {on }}, \tau, \mathrm{T}_{\mathrm{L}}$, dielectric fluid $\left(\mathrm{D}_{\mathrm{f}}\right), \mathrm{I}_{\mathrm{p}}$ and 3 different types of electrode material $(\mathrm{Cu}$, $\mathrm{CuW}$, GR) using $\mathrm{L}_{36}$ orthogonal array to find the effect on MRR, EWR, and $\mathrm{R}_{\mathrm{a}}$. GRA along with PCA has been used to optimize the model. They confirmed an increase in MRR by $109.2 \%$ and reduction in EWR, $\mathrm{R}_{\mathrm{a}}$ by $51.9 \%, 7.27 \%$ respectively by application of GRAPCA model.

From the literature survey, it is evident that almost negligible work has been reported in EDM of $\mathrm{Al} 6063-10 \mathrm{SiC}-5 \mathrm{~B}_{4} \mathrm{C}-$ Mg HMMC using different sets of electrodes and sizes and modeling optimized using GRA based PCA approach. Therefore, the present work has been aimed towards to optimize the input parameters for the matchless conditions in EDM machining of Al 6063-10SiC-5B $\mathrm{B}_{4} \mathrm{C}-\mathrm{Mg}$ HMMC using copper and graphite (of different sizes) as an electrode by GRA based PCA approach.

\section{HYBRID METAL MATRIX COMPOSITE}

The HMMC (AL-10SiC-5B $\mathrm{B}_{4} \mathrm{C}-1 \mathrm{Mg}$ ) consists of metal matrix in the form of $84 \%$ (wt) of Aluminium 6063 and reinforcement material in form of $\mathrm{SiC}$ of micron size $45 \mu \mathrm{m}$ in $10 \%$ (wt) and $\mathrm{B}_{4} \mathrm{C}$ of micron size $52 \mu \mathrm{m}$ in $5 \%$ (wt) and to improve wetability $\mathrm{Mg}$ in $1 \%(\mathrm{wt}$ ) has been used. The HMMC was developed by stir casting route. Table 1 shows the constituents of Al-6063. Table 2 shows the mechanical properties of HMMC (Reddy et al., 2018).

Table 1: Composition of Al-6063

\begin{tabular}{|c|c|c|c|}
\hline Al-6063 Composition & Wt. \% & Al-6063 Composition & Wt. \% \\
\hline $\mathrm{Al}$ & Max 97.5 & $\mathrm{Mn}$ & Max 0.1 \\
\hline $\mathrm{Cr}$ & Max 0.1 & $\mathrm{Si}$ & $0.2-0.6$ \\
\hline $\mathrm{Cu}$ & Max 0.1 & $\mathrm{Ti}$ & Max 0.1 \\
\hline $\mathrm{Fe}$ & Max 0.35 & $\mathrm{Zn}$ & Max 0.1 \\
\hline $\mathrm{Mg}$ & $0.45-0.9$ & & \\
\hline
\end{tabular}


Table 2: Mechanical Properties of HMMC ${ }^{[12]}$

\begin{tabular}{|c|c|c|c|c|c|}
\hline \multirow{2}{*}{$\begin{array}{c}\text { Hybrid Metal } \\
\text { Matrix Composite } \\
\text { Material }\end{array}$} & $\begin{array}{c}\text { Tensile } \\
\text { Strength } \\
\end{array}$ & $\begin{array}{c}\text { Yield } \\
\text { Strength } \\
\end{array}$ & Density & $\begin{array}{c}\text { Brinell } \\
\text { Hardness }\end{array}$ & $\begin{array}{c}\text { Break } \\
\text { Load } \\
\end{array}$ \\
\hline & $\left(\mathrm{N} / \mathrm{mm}^{2}\right)$ & $\left(\mathrm{N} / \mathrm{mm}^{2}\right)$ & $\left(\mathrm{Kg} / \mathrm{m}^{3}\right)$ & (HB) & $(\mathrm{kN})$ \\
\hline \multirow{4}{*}{$\begin{array}{c}\text { 84wt.\% Al-- } \\
\text { 10wt.\% SiC--5 } \\
\text { wt.\% B }{ }_{4} \mathrm{C}\end{array}$} & 120.32 & 98.75 & 2537.5 & 71.58 & 9.45 \\
\hline & $\begin{array}{c}\text { Maximum } \\
\text { displacement }\end{array}$ & Elongation & $\begin{array}{c}\text { Flexural break } \\
\text { load }\end{array}$ & $\begin{array}{l}\text { Flexural } \\
\text { Maximum } \\
\text { deflection }\end{array}$ & $\begin{array}{l}\text { Flexural } \\
\text { strength }\end{array}$ \\
\hline & $(\mathrm{mm})$ & $\%$ & $(\mathrm{kN})$ & $(\mathrm{mm})$ & (MPa) \\
\hline & 9.7 & 7.53 & 3.68 & 5.6 & 214.12 \\
\hline
\end{tabular}

\section{EXPERIMENTAL SETUP}

This section covers the EDM of HMMC using Ecoline die-sinking EDM, model: ECO 250 series with three-phase power input with maximum current of $35 \mathrm{Amp}$, as shown in Figure 1. With direct polarity, electrodes (pure copper and graphite) of different sizes $(15 \mathrm{~mm}$ and $10 \mathrm{~mm}$ ) Figure 4, is used for experimentation; the experimental facility used is shown in Table 3. Based on exhaustive pilot experiments, Taguchi $\mathrm{L}_{16} \mathrm{OA}$ is used for the Design of Experiments (DOE) with 6 factors out of which 3 factors are of 4 levels and 3 factors of 2 levels each. (Wakjira et al., 2019) The Input parameters selected for the experimentation includes current $\left(\mathrm{I}_{\mathrm{p}}\right)$, pulse on time $\left(\mathrm{T}_{\mathrm{on}}\right)$, duty factor $(\tau)$, spark gap $\left(\mathrm{S}_{\mathrm{g}}\right)$, electrode type $(\mathrm{ET})$ and electrode size (ES). EDM input parameters with corresponding levels is shown in Table 4.

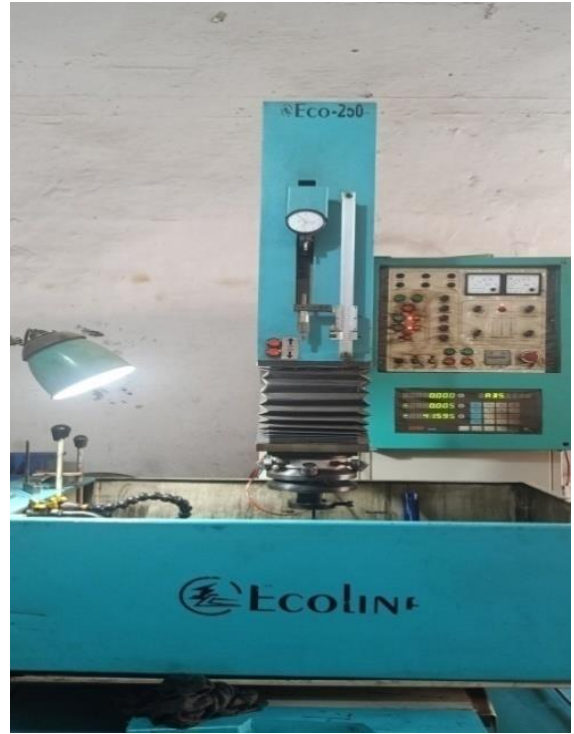

Figure 1: Ecoline Di Sinking EDM Model ECO 250.

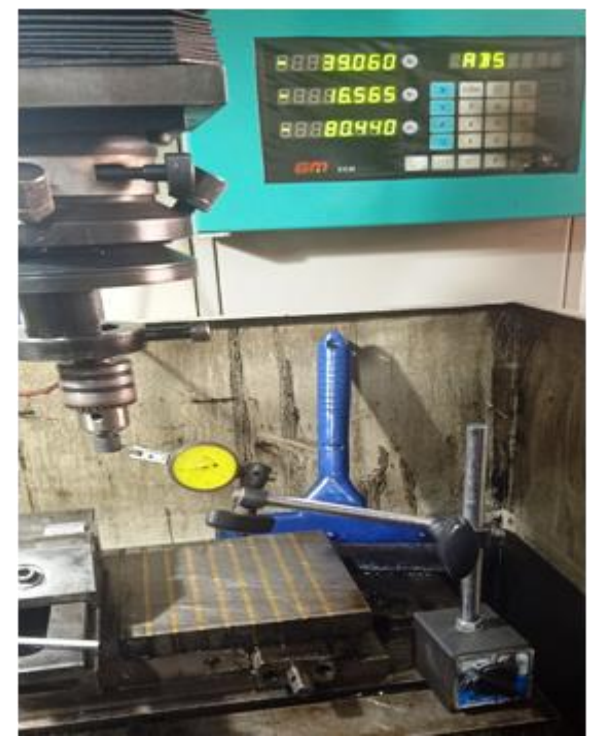

Figure 2: Leveling Operation of Electrode.

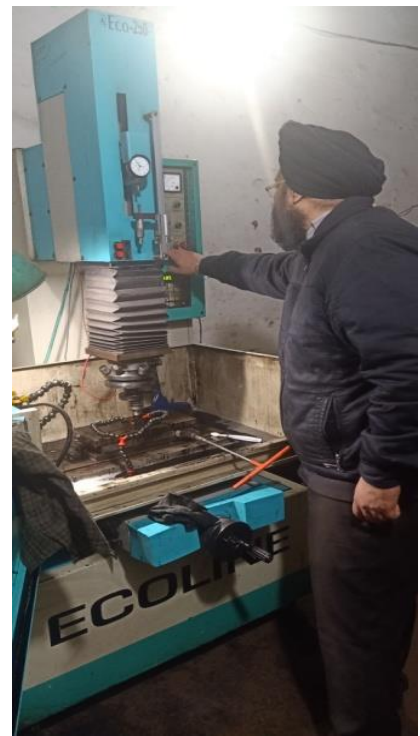

Figure 3: Setting the Input Parameters.

Table 3: Experimental Facility used

\begin{tabular}{|l|l|}
\hline \multicolumn{1}{|c|}{ Facility } & \multicolumn{1}{c|}{ Specifications } \\
\hline EDM Machine & Ecoline ECO 250 series \\
\hline \multirow{2}{*}{ Surface roughness tester } & Mitutoyo SJ-201 Sr.no 500829 surface finish meter \\
\cline { 2 - 2 } & $(-200 \mu \mathrm{m}$ to $+150 \mu \mathrm{m})$ \\
\hline Digital weigh balancer & Generic Digital Scale 0.001gm To 200gm \\
\hline Electrode & $\begin{array}{l}\text { 2 piece }(15 \mathrm{~mm}, 10 \mathrm{~mm}) \text { each of copper and graphite( } \\
\text { Figure 4) }\end{array}$ \\
\hline Flushing speed & $\begin{array}{l}\text { Flow rate of } 1.2 \mathrm{Kg} / \mathrm{cm}^{2} \text { kept constant through all } \\
\text { experiments. }\end{array}$ \\
\hline Dielectric medium & Kerosene based EDM oil \\
\hline
\end{tabular}


Table 4: EDM Input Parameters with Levels

\begin{tabular}{|l|c|c|c|c|c|}
\hline \multicolumn{1}{|c|}{ I/P parameters } & Units & Level 1 & Level 2 & Level 3 & Level 4 \\
\hline Current (I) & $\mathrm{amp}$ & 3 & 6 & 9 & 12 \\
\hline Pulse on Time( $\left.\mathrm{T}_{\text {on }}\right)$ & $\mu \mathrm{s}$ & 25 & 50 & 75 & 100 \\
\hline Duty Factor $(\mathrm{T})$ & $\%$ & 2 & 4 & 6 & 8 \\
\hline Spark Gap $\left(\mathrm{S}_{\mathrm{g}}\right)$ & $\mathrm{mm}$ & 3 & 6 & & \\
\hline Electrode Type $(\mathrm{ET})$ & & $\mathrm{Cu}$ & $\mathrm{Gr}$ & & \\
\hline Electrode Size $(\mathrm{ES})$ & $\mathrm{mm}$ & 10 & 15 & & \\
\hline
\end{tabular}

The HMMMC 16 samples (Figure 5) were cut into equal sizes of $20 \times 30$ X 4 mm using wire EDM to maintain the composite grain structure. As per the T-M L ${ }_{16} \mathrm{OA}$ the proper electrode is first selected. (Figure 4). The selected electrode and sample initial weight $\left(\mathrm{E}_{\mathrm{b}} \& \mathrm{~W}_{\mathrm{b}}\right)$ were measured using electronic weight balancer (0.001gm to 200gm) Figure 6.

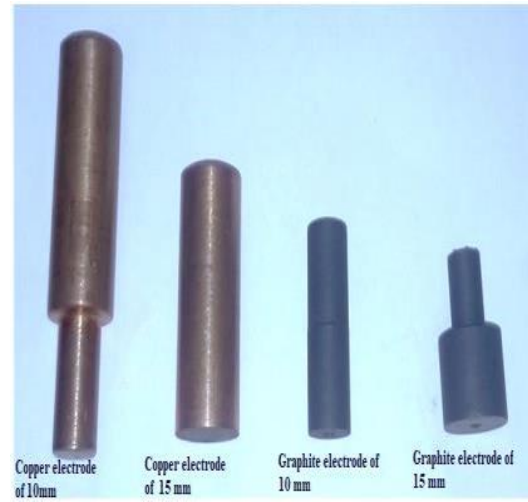

Figure 4: Copper and Graphite Electrode of $15 \mathrm{~mm}$ and $10 \mathrm{~mm}$ Diameter.

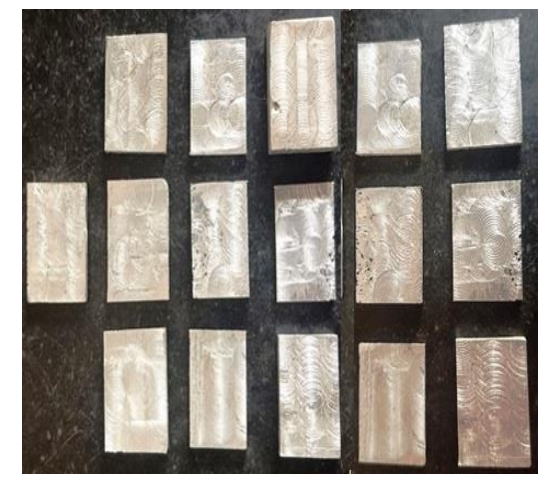

Figure 5: HMMC Samples for EDM.

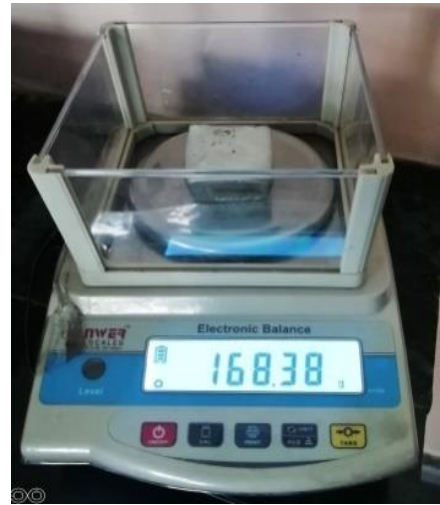

Figure 6: Electronic Weight Balancer.

Table 5: L16 Orthogonal Array Observation Table

\begin{tabular}{|c|c|c|c|c|c|c|c|c|c|}
\hline \multirow{2}{*}{ Exp. No. } & I & Ton & T & Sg & ET & ES & MRR & EWR & Ra \\
\cline { 2 - 10 } & $(\mathbf{A m p})$ & $(\boldsymbol{\mu s})$ & $(\boldsymbol{\%})$ & $(\mathbf{m m})$ & & $(\mathbf{m m})$ & $(\mathbf{m m 3} / \mathbf{m i n})$ & $(\mathbf{m m 3 / m i n})$ & $(\boldsymbol{\mu m})$ \\
\hline 1 & 3 & 25 & 2 & 3 & CU & 10 & 2.5684 & 0.55803 & 4.36 \\
\hline 2 & 3 & 50 & 4 & 3 & CU & 15 & 1.2804 & 0.57603 & 4.68 \\
\hline 3 & 3 & 75 & 6 & 6 & GR & 10 & 5.7618 & 0.48567 & 5.06 \\
\hline 4 & 3 & 100 & 8 & 6 & GR & 15 & 5.3911 & 0.45755 & 5.41 \\
\hline 5 & 6 & 25 & 4 & 6 & GR & 10 & 4.8794 & 0.32543 & 4.25 \\
\hline 6 & 6 & 50 & 2 & 6 & GR & 15 & 4.2574 & 0.37453 & 6.25 \\
\hline 7 & 6 & 75 & 8 & 3 & CU & 10 & 5.4712 & 0.58076 & 8.16 \\
\hline 8 & 6 & 100 & 6 & 3 & CU & 15 & 5.2766 & 0.62146 & 8.86 \\
\hline 9 & 9 & 25 & 6 & 3 & GR & 15 & 5.8746 & 0.35749 & 4.09 \\
\hline 10 & 9 & 50 & 8 & 3 & GR & 10 & 6.1895 & 0.87942 & 5.16 \\
\hline 11 & 9 & 75 & 2 & 6 & CU & 15 & 7.2476 & 1.26113 & 7.25 \\
\hline 12 & 9 & 100 & 4 & 6 & CU & 10 & 7.5454 & 1.69491 & 5.63 \\
\hline 13 & 12 & 25 & 8 & 6 & CU & 15 & 6.1475 & 0.38764 & 8.09 \\
\hline 14 & 12 & 50 & 6 & 6 & CU & 10 & 6.4173 & 0.53538 & 9.21 \\
\hline 15 & 12 & 75 & 4 & 3 & GR & 15 & 8.2144 & 2.23657 & 12.15 \\
\hline 16 & 12 & 100 & 2 & 3 & GR & 10 & 8.1475 & 2.82487 & 12.45 \\
\hline
\end{tabular}


The workpiece and electrode were mounted on the workbench and chuck respectively, and alignment and leveling were being done. (Figure 2) As per the design of experiment (Table 5), the input parameters were fed into the EDM (Figure 3). Before starting the EDM machine, the input voltage was being checked for any faults in terms of fluctuations, etc. The side flushing method is being used by manually setting the flow of flushing pressure directly on the top of the surface of the workpiece for maximum cleaning action and thus better $\mathrm{R}_{\mathrm{a}}$. The EDM was then switched on, and the electrode was set near to the workpiece, and lift was adjusted accordingly. The flushing motor \& spark action was then started. The machine was allowed to run for 15 minutes. During this period, the electrode approaches near to the surface of the workpiece, created a spark, and then lifts off. During lift off the flushing mechanism flushes the debris of the workpiece from its surface. After 15 minutes of EDM action, the machine was switched off and the workpiece and electrode were removed from the EDM and weighted $\left(\mathrm{W}_{\mathrm{a}}\right.$ and $\mathrm{E}_{\mathrm{a}}$ ) again for final weight measurement with the electronic weigh balancer. The MRR and EWR were calculated from Equation (1,2), respectively. $\mathrm{R}_{\mathrm{a}}$ was calculated using Mitutoyo SJ-201 surface finish meter.

$$
\begin{aligned}
& M R R=\frac{W_{b}-W_{a}}{\rho \times t} \\
& E W R=\frac{E_{b}-E_{a}}{\rho \times t}
\end{aligned}
$$

Where, $\mathrm{w}_{\mathrm{b}}$ and $\mathrm{w}_{\mathrm{a}}=$ Initial \& final weight of samples in $\mathrm{gm}$

$E_{b}$ and $E_{a}=$ Initial \& final weight of electrode in gm

$\rho=$ Density of workpiece material in $\mathrm{gm} / \mathrm{mm}^{3}$

$\mathrm{t}=$ Time of machining in minutes.

The Table 5 also shows the observations table of experimentation performed. Figure 7 shows pictures of 16HMMC samples after EDM operation.

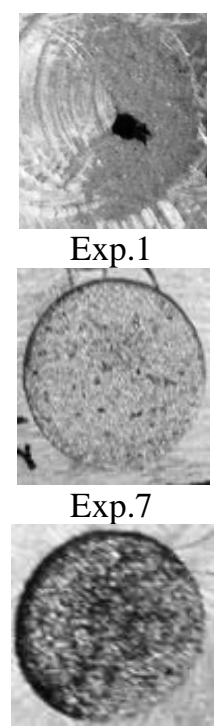

Exp.13

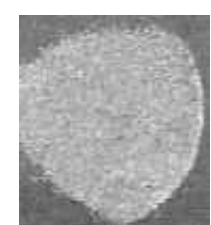

Exp.2

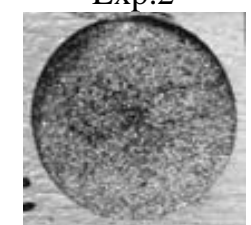

Exp.8

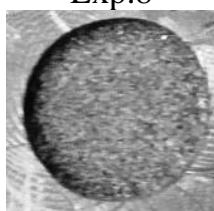

Exp. 14

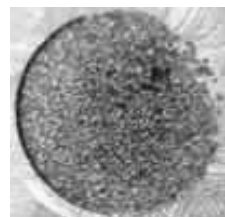

Exp. 3

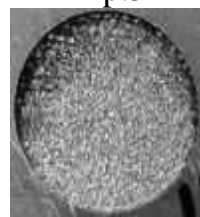

Exp.9

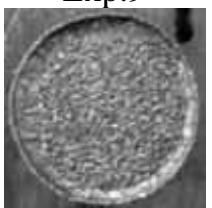

Exp.15

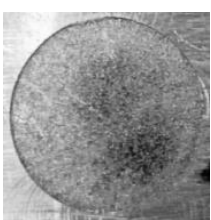

Exp.4

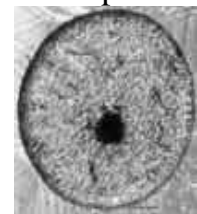

Exp.10

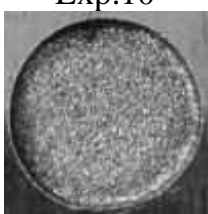

Exp.16

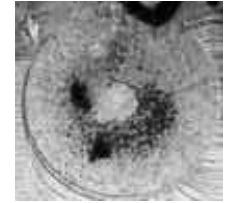

Exp.5

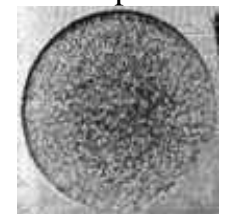

Exp.11

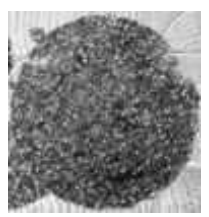

Exp.6

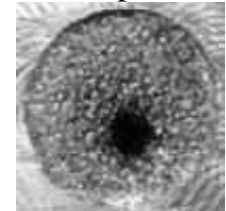

Exp.12

Figure 7: HMMC Samples after Machining at different Input Variables. 


\section{OPTIMIZATION USING GRA-PCA APPROACH}

This section covers the optimization of the model using the GRA-PCA approach. Optimization is a technique in which an alternative is ascertained under the accepted constraints to have a higher achievable performance with the least cost involved. The various factors are streamlined, and the best factors are maximized, and undesired ones are being minimized. The motive of this study is to maximize the MRR and reduce the EWR and $\mathrm{R}_{\mathrm{a}}$. The composite $\mathrm{Al}-10 \mathrm{SiC}-5 \mathrm{~B} 4 \mathrm{C}-\mathrm{Mg}$, prepared through the stir casting route, is machined using copper \& graphite electrode of different diameters, as per DOE. A hybrid multi-response optimization approach such as principal component analysis (PCA) based grey relational analysis (GRA) has been attempted for composite $\mathrm{Al}-10 \mathrm{SiC}-5 \mathrm{~B}_{4} \mathrm{C}-\mathrm{Mg}$ by the EDM process.

\section{GREY RELATIONAL ANALYSIS}

In the GRA approach, the analysis is being done by comparing the relational degree in distinct succession. In this technique, the data needs to be pretreated since the span and unit in one data succession may vary from the others. In this case, the key objective is to increase the MRR and EWR, $\mathrm{R}_{\mathrm{a}}$ needs to be minimized. Due to different objectives, the output parameters need to be normalized using the following. Equation $(3,4)$.(Bhuyan et al., 2014)

$$
\begin{aligned}
& \frac{y_{i}^{p}(r)-\min y_{i}^{p}(r)}{\max y_{i}^{p}(r)-\min y_{i}^{p}(r)}=y_{i}^{*}(r) \text { for higher the better approach }(\mathrm{Hb}) \\
& \frac{\max y_{i}^{p}(r)-y_{i}^{p}(r)}{\max y_{i}^{p}(r)-\min y_{i}^{p}(r)}=y_{i}^{*}(r) \text { for lower the better approach(Lb) }
\end{aligned}
$$

where $y_{i}^{*}(r)$ is the value after normalization. $y_{i}^{p}(r)$ is the corresponding table value, $\min y_{i}^{p}(r) \& \max y_{i}^{p}(r)$ are the minimum and maximum values in a column of a parameter under study. Table 6 shows the normalized value of each output parameter.

Table 6: Sequence of Output Parameters after Normalization

\begin{tabular}{|c|c|c|c|c|c|c|c|c|c|c|c|}
\hline Exp. No & \multicolumn{2}{|c|}{ Output Parameters Value } & \multicolumn{2}{|c|}{ Comparability Sequence } & \multicolumn{3}{|c|}{ Deviation Sequence } \\
\hline & MRR & EWR & Ra & MRR & EWR & Ra & MRR & EWR & Ra \\
\hline 1 & 2.5684 & 0.55803 & 4.36 & 0.8142 & 0.9069 & 0.9677 & 0.8142 & 0.0931 & 0.0323 \\
\hline 2 & 1.2804 & 0.55803 & 4.68 & 1.0000 & 0.9069 & 0.9294 & 1.0000 & 0.0931 & 0.0706 \\
\hline 3 & 5.7618 & 0.48567 & 5.06 & 0.3537 & 0.9359 & 0.8840 & 0.3537 & 0.0641 & 0.1160 \\
\hline 4 & 5.39119 & 0.45755 & 5.41 & 0.4072 & 0.9471 & 0.8421 & 0.4072 & 0.0529 & 0.1579 \\
\hline 5 & 4.8794 & 0.32543 & 4.25 & & 0.4810 & 1.0000 & 0.9809 & 0.4810 & 0.0000 & 0.0191 \\
\hline 6 & 4.2574 & 0.37453 & 6.25 & & 0.5707 & 0.9804 & 0.7416 & 0.5707 & 0.0196 & 0.2584 \\
\hline 7 & 5.4712 & 0.58076 & 8.16 & 0.3956 & 0.8978 & 0.5132 & 0.3956 & 0.1022 & 0.4868 \\
\hline 8 & 5.2766 & 0.62146 & 8.86 & & 0.4237 & 0.8816 & 0.4294 & 0.4237 & 0.1184 & 0.5706 \\
\hline 9 & 5.8746 & 0.35749 & 4.09 & 0.3374 & 0.9872 & 1.0000 & 0.3374 & 0.0128 & 0.0000 \\
\hline 10 & 6.1895 & 0.87942 & 5.16 & 0.2920 & 0.7784 & 0.8720 & 0.2920 & 0.2216 & 0.1280 \\
\hline 11 & 7.2476 & 1.26113 & 7.25 & & 0.1394 & 0.6256 & 0.6220 & 0.1394 & 0.3744 & 0.3780 \\
\hline 12 & 7.5454 & 1.69491 & 5.63 & 0.0965 & 0.4521 & 0.8158 & 0.0965 & 0.5479 & 0.1842 \\
\hline 13 & 6.1475 & 0.38764 & 8.09 & 0.2981 & 0.9751 & 0.5215 & 0.2981 & 0.0249 & 0.4785 \\
\hline 14 & 6.4173 & 0.53538 & 9.21 & 0.2592 & 0.9160 & 0.3876 & 0.2592 & 0.0840 & 0.6124 \\
\hline 15 & 8.2144 & 2.23657 & 12.15 & 0.0000 & 0.2354 & 0.0359 & 0.0000 & 0.7646 & 0.9641 \\
\hline 16 & 8.1475 & 2.82487 & 12.45 & 0.0096 & 0.0000 & 0.0000 & 0.0096 & 1.0000 & 1.0000 \\
\hline
\end{tabular}


The normalized sequence is being used to calculate the grey relational coefficient $\left(\Psi_{0 i} r\right)$ Equation $5, \Delta_{0, i}(r)$ is the corresponding continuance sequence minus comparatibility sequence. It is given by $\Delta_{0, i}(r)=\left|y_{0}^{*}(r)-y_{i}^{*}(r)\right|$, $\Delta \max =\max \left|y_{0}^{*}(r)-y_{i}^{*}(r)\right|$ and $\Delta \min =\min \left|y_{0}^{*}(r)-y_{i}^{*}(r)\right|$. In this case the distinguishing coefficient $(\zeta)$ has been assumed the value of $(0.5)$. Table 7 displays the corresponding value of grey relational coefficient. ${ }^{[14]}$

$$
\Psi_{0 i} r=\frac{\Delta \min +\zeta \Delta \max }{\Delta_{0, i}(r)+\zeta \Delta \max }
$$

Table 7: GR Sequence, Grey Relational Grade, Rank for All Experiments

\begin{tabular}{|c|c|c|c|c|c|}
\hline \multirow{2}{*}{$\begin{array}{l}\text { Exp. } \\
\text { No }\end{array}$} & \multicolumn{3}{|c|}{ Grey Relation Sequence } & \multirow{2}{*}{$\begin{array}{c}\text { Grey Relational } \\
\text { Grade }\end{array}$} & \multirow{2}{*}{ Rank } \\
\hline & MRR & EWR & SR & & \\
\hline 1 & 0.3804 & 0.8431 & 0.9393 & 0.7276 & 5 \\
\hline 2 & 0.3333 & 0.8431 & 0.8763 & 0.6916 & 9 \\
\hline 3 & 0.5857 & 0.8864 & 0.8117 & 0.7655 & 3 \\
\hline 4 & 0.5512 & 0.9044 & 0.7600 & 0.7435 & 4 \\
\hline 5 & 0.5097 & 1.0000 & 0.9631 & 0.8313 & 2 \\
\hline 6 & 0.4670 & 0.9622 & 0.6593 & 0.7031 & 7 \\
\hline 7 & 0.5583 & 0.8304 & 0.5067 & 0.6355 & 13 \\
\hline 8 & 0.5413 & 0.8085 & 0.4670 & 0.6093 & 14 \\
\hline 9 & 0.5971 & 0.9750 & 1.0000 & 0.8628 & 1 \\
\hline 10 & 0.6313 & 0.6929 & 0.7962 & 0.7078 & 6 \\
\hline 11 & 0.7819 & 0.5718 & 0.5695 & 0.6382 & 12 \\
\hline 12 & 0.8382 & 0.4771 & 0.7308 & 0.6772 & 10 \\
\hline 13 & 0.6265 & 0.9526 & 0.5110 & 0.7011 & 8 \\
\hline 14 & 0.6586 & 0.8562 & 0.4495 & 0.6574 & 11 \\
\hline 15 & 1.0000 & 0.3954 & 0.3415 & 0.5704 & 15 \\
\hline 16 & 0.9811 & 0.3333 & 0.3333 & 0.5401 & 16 \\
\hline
\end{tabular}

\section{PRINCIPAL COMPONENT ANALYSIS}

In PCA, the reduction in variables takes place by taking out the most important one from a large sample size. It helps in retaining the most data, as well as reducing the size of the data without altering the accuracy. In PCA, the actual data is converted into uncorrelated variables or Principal component ( $\square_{\square \square}$ ) Equation7 by computing the eigenvectors of the covariance matrix of the original data. The eigenvalues $\left(\square_{\square}\right)$ or characteristic value is any value that makes the matrix "A" solution possible. The eigenvector $\left(\square_{\square \square}\right)$ Equation 6 corresponds to the value. The eigenvalue problem is generally denoted as

$$
\begin{aligned}
& V_{i p}\left(A-\lambda_{p} I_{n}\right)=0 \\
& Y_{p c}=\sum_{i=1}^{p} y_{n}(i) V_{i p} \\
& \phi_{0, i}=\frac{1}{q} \sum_{n=1}^{q} W_{n} \Psi_{o, i}(n)
\end{aligned}
$$


Table 8: Eigen value, Proportion( $\%$, Cumulative, Eigenvector

\begin{tabular}{|l|c|c|c|c|}
\hline $\begin{array}{c}\text { Principal } \\
\text { Component }\end{array}$ & Eigenvalue & $\begin{array}{c}\text { Proportion } \\
(\boldsymbol{\%})\end{array}$ & Cumulative & Eigen Vector \\
\hline First & 2.3156 & 0.772 & 0.772 & {$[0.565,0.796,-0.216]$} \\
\hline Second & 0.3889 & 0.13 & 0.902 & {$[0.589,-0.206,0.782]$} \\
\hline Third & 0.2955 & 0.098 & 1 & {$[0.578,-0.569,-0.585]$} \\
\hline
\end{tabular}

The grey relational grade $\left(\phi_{0, i}\right)$ has been calculated as per Equation 8, Table 8 shows that the square of eigenvector correlates to the input of corresponding principal component $\left(Y_{p c}\right)$.

Table 9: Grey Relational Grade Response Table

\begin{tabular}{|l|c|c|c|c|c|c|}
\hline \multirow{2}{*}{ Input Parameters } & \multicolumn{3}{|c|}{ Grey Relational Grade } & \multirow{2}{*}{$\begin{array}{c}\text { Max- } \\
\text { Min } \\
\text { (Delta } \\
\text { value) }\end{array}$} & Rank \\
\cline { 2 - 7 } & Level 1 & Level 2 & Level 3 & Level 4 & 0.1148 & 1 \\
\hline Current (I) & $0.7321 *$ & 0.6948 & 0.7215 & 0.6173 & 0.1382 & 3 \\
\hline Pulse on time(Ton) & $0.7807 *$ & 0.6899 & 0.6524 & 0.6425 & 0.67 \\
\hline Duty Factor(T ) & 0.6523 & 0.6926 & $0.7237 *$ & 0.697 & 0.0715 & 4 \\
\hline Spark Gap(Sg) & 0.6681 & $0.7147 *$ & & & 0.0465 & 5 \\
\hline Electrode Type (ET) & 0.6672 & $0.7156 *$ & & & 0.0484 & 2 \\
\hline Electrode Shape (ES) & $0.6928 *$ & 0.69 & & & 0.0028 & 6 \\
\hline *optimum parameter value & & & & & \\
\hline
\end{tabular}

\section{RESULTS AND DISCUSSIONS}

In case of first $Y_{p c}$, the contribution of variance clearly explains the initial variables, i.e., $77.1 \%$, therefore it has been decided to include the square of all eigenvectors to calculate $\phi_{0, i}$, the corresponding weight of output parameter $\left(W_{n}\right)$ calculated for three principal components is taken to be $M R R=0.319, E W R=0.346$ and $R_{a}=0.334$. The grey relational grade $\left(\phi_{0, i}\right)$ and corresponding Rank is shown in Table 7. The substantial estimate of Grey relational grade shows the best performance irrespective of the output parameter category. ${ }^{[14]}$ Table 9.shows the values of optimum input parameters and their effect on grey relational grade. Figure 8 shows the related graph.

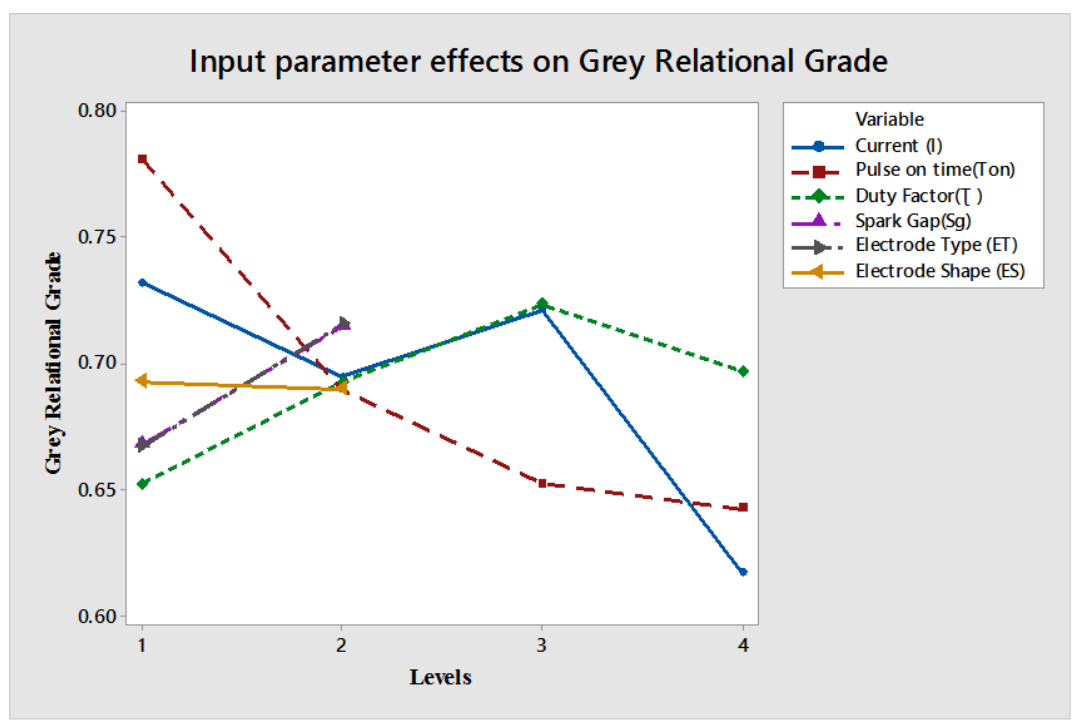

Figure 8: Input Parameter Effects on Grey Relational Grade. 


\section{CONFIRMATION OF EXPERIMENTATION}

It is evident from the Table 9 the most favorable input parameters for best grey relational grade is $I_{p}=5$ Amp (level 1 ), $\mathrm{T}_{\mathrm{on}}=25 \mu$ s (level 1), $\mathrm{T}=6$ (level 3), $\mathrm{S}_{\mathrm{g}}=6 \mathrm{~mm}$ (level 2), $\mathrm{ET}=$ Graphite, $\mathrm{ES}=10 \mathrm{~mm}$.

Table 10: ANOVA Results for GRG

\begin{tabular}{|l|c|c|c|c|c|}
\hline Source & DF & Adj SS & Adj MS & F-Value & P-Value \\
\hline Current & 3 & 0.032267 & 0.010756 & 14.31 & 0.028 \\
\hline Pulse on time & 3 & 0.047555 & 0.015852 & 21.09 & 0.016 \\
\hline Duty Factor & 3 & 0.010441 & 0.00348 & 4.63 & 0.12 \\
\hline Spark Gap & 1 & 0.008655 & 0.008655 & 11.52 & 0.043 \\
\hline Electrode Type & 1 & 0.009351 & 0.009351 & 12.44 & 0.039 \\
\hline Electrode Size & 1 & 0.000032 & 0.000032 & 0.04 & 0.851 \\
\hline Error & 3 & 0.002255 & 0.000752 & & \\
\hline Total & 15 & 0.110555 & & & \\
\hline
\end{tabular}

ANOVA is applied (Minitab 18) to determine the most significant input parameter, which affects the output parameters. Table 10 shows the ANOVA results for the grey relational grade. It shows that for the model, $\mathrm{T}_{\text {on }}(21 \%)$ and $\mathrm{I}_{\mathrm{p}}$ (14.3\%) are the most influential parameters followed by ET $(12.44 \%), \mathrm{S}_{\mathrm{g}}(11.52 \%)$ and $\mathrm{T}(4.6 \%)$. It is a requirement to intensify the output variable by using the optimized input variables. Table 11 and Figure 9 depict the testimony of trials, which are acquired by designing the conclusions from the optimized and preliminary process parameters.

Table 11: Result of Confirmation Experiments

\begin{tabular}{|l|c|c|c|c|c|}
\hline Best Combination & & MRR & EWR & RA \\
\hline Initial Design & & $\mathrm{I}_{1} \mathrm{~T}_{\text {on } 1} T_{1} \mathrm{~S}_{\mathrm{g} 1} \mathrm{ET}_{1} \mathrm{ES}_{1}$ & 2.568 & 0.558 & 4.36 \\
\hline Optimal design & & $\mathrm{I}_{3} \mathrm{~T}_{\text {on } 1} \mathrm{~T}_{3} \mathrm{~S}_{\mathrm{g} 2} \mathrm{ET}_{2} \mathrm{ES}_{1}$ & 6.997 & 0.1999 & 2.86 \\
\hline Final improvement & & $\mathbf{1 7 2 . 5 0 \%}$ & $\mathbf{6 4 . 1 7 \%}$ & $\mathbf{3 4 . 4 0 \%}$ \\
\hline
\end{tabular}

It is noticeable that the MRR has shown improvement of about $172.5 \%$ whereas EWR has shown substantial decrease of $64.17 \%$ The $\mathrm{R}_{\mathrm{a}}$ has also reduced by $34.4 \%$. Thus, it is evident that Principal Component Analysis (PCA) based Grey Relational Analysis (GRA) has been successfully applied to multi-optimization of Aluminum based composite EDM process.

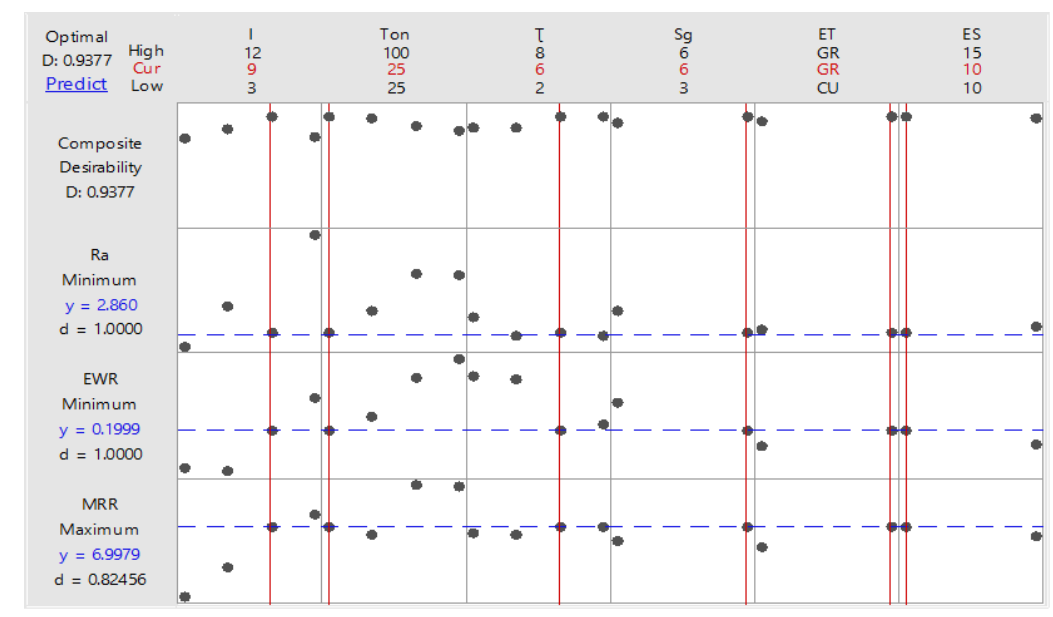

Figure 9: Optimum Value of Input Parameters. 


\section{CONCLUSIONS}

The Hybrid Metal Matrix Composite (Al-10SiC-B 4 C-1Mg) was successfully tested on Electric Discharge Machining using Copper and Graphite electrode of different sizes. Grey relational analysis coupled with Principal component analysis was successfully applied for optimization with following observations.

- It can be mentioned from analysis of variance that out of 6 input variables $\mathrm{T}_{\text {on }}(21 \%)$ and $\mathrm{I}_{\mathrm{p}}(14.3 \%)$ are the most influential parameters followed by ET (12.44\%), $\mathrm{S}_{\mathrm{g}}(11.52 \%)$ and T (4.6\%) on output parameters MRR,EWR and $\mathrm{R}_{\mathrm{a}}$.

- $\quad$ The Electrode size has negligible influence as compared to other input parameters on output parameters.

- The Principal Component Analysis is applied to enumerate the related weights of discrete output parameters such as for MRR (0.319), EWR (0.346) \& $\mathrm{R}_{\mathrm{a}}(0.334)$ during application of Grey relational analysis for multi-response optimization are proficient enough to indicate the importance for each output parameters.

- The optimal mixture of input parameters as devised through the GRA-PCA approach is $\mathrm{I}_{3} \mathrm{~T}_{\mathrm{on} 1} \mathrm{~T}_{3} \mathrm{~S}_{\mathrm{g} 2} \mathrm{ET}_{2} \mathrm{ES}_{1}$. Through acceptance trial, it is observed that MRR improves by $172.5 \%$ and EWR reduced by $64.17 \%$ and $\mathrm{R}_{\mathrm{a}}$ reduced by $34.4 \%$.

- The Grey relational grade rank is highest for Exp. No. 9 (0.8628) and corresponding values of output parameters observed experimentally is $\mathrm{MRR}=5.87 \mathrm{~mm}^{3} / \mathrm{min}, \mathrm{EWR}=0.357 \mathrm{~mm}^{3} / \mathrm{min}$ and $\mathrm{R}_{\mathrm{a}}=4.09 \mu \mathrm{m}$ and corresponding values of Input variables are $\mathrm{I}=9 \mathrm{amp}, \mathrm{T}_{\mathrm{on}}=25 \mu \mathrm{s}, \mathrm{T}=6, \mathrm{~S}_{\mathrm{g}}=3 \mathrm{~mm}, \mathrm{ET}=$ Graphite and $\mathrm{ES}=15 \mathrm{~mm}$

\section{REFERENCES}

1. Nturanabo, F., Masu, L., \& Baptist Kirabira, J. (2019). Novel Applications of Aluminium Metal Matrix Composites. Aluminum Alloys and Composites [Working Title]. doi: 10.5772/intechopen.86225

2. Joshi, A. Y., \& Joshi, A. Y. (2019). A systematic review on powder mixed electrical discharge machining. Heliyon, 5(12), e02963. doi: 10.1016/j.heliyon.2019.e02963

3. Sahu, D., Sahu, S. K., Jadam, T., \& Datta, S. (2019). Electro-Discharge Machining Performance of Nimonic 80A: An Experimental Observation. Arabian Journal for Science and Engineering, 44(12), 10155-10167. doi: 10.1007/s13369-01904112-1

4. Dikshit, M. K., Anand, J., Narayan, D., \& Jindal, S. (2019). Machining characteristics and optimization of process parameters in die-sinking EDM of Inconel 625. Journal of the Brazilian Society of Mechanical Sciences and Engineering, 41(7), 1-14. doi: 10.1007/s40430-019-1809-5

5. Singh, G., Bhui, A. S., \& Singh, M. (2019). Analysis of electrical discharge machining parameters for H13 steel using OVAT technique. Engineering Research Express, 1(2), 025031. doi: 10.1088/2631-8695/ab52dc

6. Choudhary, R., Garg, H., Prasad, M., \& Kumar, D. (2017). Effect of Cryogenic Treatment of Tool Electrode on the Machining Performance and Surface Finish during Electrical Discharge Machining of Hastelloy C-4. Materials Today: Proceedings, 4(2), 1158-1166. doi: 10.1016/j.matpr.2017.01.132

7. Ram Prasad, A. V. S., Ramji, K., Kolli, M., \& Vamsi Krishna, G. (2019). Multi-Response Optimization of Machining Process Parameters for Wire Electrical Discharge Machining of Lead-Induced Ti-6Al-4V Alloy Using AHP-TOPSIS Method. Journal of Advanced Manufacturing Systems, 18(2), 213-236. doi: 10.1142/S0219686719500112 
8. Singh Bains, P., Sidhu, S. S., \& Payal, H. S. (2018). Investigation of magnetic field-assisted EDM of composites. Materials and Manufacturing Processes, 33(6), 670-675. doi: 10.1080/10426914.2017.1364857

9. Meshram, D. B., \& Puri, Y. M. (2020). Optimized curved electrical discharge machining-based curvature channel. Journal of the Brazilian Society of Mechanical Sciences and Engineering, 42(2), 1-13. doi: 10.1007/s40430-019-2162-4

10. Kumar, P. M., Sivakumar, K., \& Jayakumar, N. (2018). Multiobjective optimization and analysis of copper-titanium diboride electrode in EDM of monel 400 ${ }^{T M}$ alloy. Materials and Manufacturing Processes, 33(13), 1429-1437. doi: 10.1080/10426914.2017.1415439

11. Payal, H., Maheshwari, S., \& Bharti, P. S. (2019). Parametric optimization of EDM process for Inconel 825 using GRA and PCA approach. Journal of Information and Optimization Sciences, 40(2), 291-307. doi: 10.1080/02522667.2019.1578090

12. Reddy, P. S., Kesavan, R., \& Vijaya Ramnath, B. (2018). Investigation of Mechanical Properties of Aluminium 6061-Silicon Carbide, Boron Carbide Metal Matrix Composite. Silicon, 10(2), 495-502. doi: 10.1007/s12633-016-9479-8

13. Wakjira, M. W., Altenbach, H., \& Perumalla, J. R. (2019). Analysis of CSN 12050 carbon steel in dry turning process for product sustainability optimization using taguchi technique. Journal of Engineering (United Kingdom), 2019. doi: $10.1155 / 2019 / 7150157$

14. Bhuyan, B. K., \& Yadava, V. (2014). Experimental modelling and multi-response optimization of travelling wire electrochemical spark machining of Pyrex glass. Proceedings of the Institution of Mechanical Engineers, Part B: Journal of Engineering Manufacture, 228(8), 902-916. doi: 10.1177/0954405413514745

15. Sudindra $S \& C$ Anil Kumar, "Studies on Al6061/Al2O3 and Graphite Hybrid Metal Matrix Composites", International Journal of Metallurgical \& Materials Science and Engineering, Vol. 3, No. 3, pp. 35-42

16. Parveen Saini \& Suraj Choudhary, “Analysis of Machining Parameters for the Optimization of Surface Roughness of Stainless Steel AISI 202 in CNC Face Milling Process", International Journal of Mechanical Engineering(IJME), Vol. 2, No. 3, pp. 27-34

17. Amal T. S, Vidya V\& Abraham K Varughese, "Machining Parameters Optimization in End Milling of Ti6al4v Using Taguchi Method", IMPACT : International Journal of Research in Engineering \& Technology(.),Vol. 3, No. 8, pp. 31-40

18. Samer Hamid Al-Ameedi, Saba Mohammad Shaheed \& Mohammed Ali Mutar, "Investigate About Some Mechanical Properties of Hardened Concrete with Plastic and Metal Trash", International Journal of Civil Engineering (IJCE), Vol. 7, No. 2, pp. 13-22

\section{AUTHORS PROFILE}

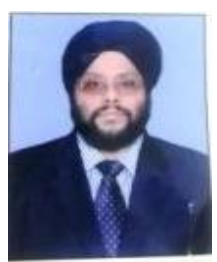

Mr. Gurpreet Singh Matharou, is presently working as Asst. Professor in Department of Automobile Engineering, FET, Manav Rachna International Institute of Research and Studies, Faridabad (HR). He did B.E. in Automobile from Gulbarga University, Karnataka, M.Tech (Industrial Engineering) from NIMS University Jaipur, PGPM (International Business and Operations) from IMT Ghaziabad. He has got more than 11 publications in Journals and Conference of repute, 5 in International Journals, 2 National Journals, 2 International Conference, 2 National Conference. His area of interest includes 
Automobiles, Modern Machining Methods, Design and Development, Design of Experiment.

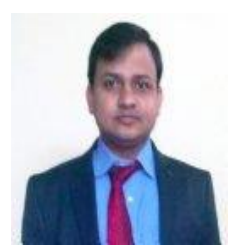

Dr. Basanta Kumar Bhuyan, is presently working as Professor in Dept. of Mechanical Engineering, FET, Manav Rachna International Institute of Research and Studies, Faridabad (HR) India. He obtained his Doctorate degree from Motilal Nehru National Institute of Technology (MNNIT) Allahabad. He did his M.Tech in Manufacturing and Automation from Career Institute of Technology and Management, Faridabad, MDU University, Rohtak and B.Tech in Mechanical Engineering from ITER, Bhubaneswar, BPUT Rourkela, Odisha. He has got more than 35 publications in Journals and conference of repute, 9 in International Journals, 1 National Journals, 18 International Conference, 7 National Conference. His area of interest includes Advanced Machining Processes, Manufacturing Science and Technology, Production Engineering, Fluid Machines, Automatic Control, Engineering Drawing, Soft Computing Method, Design of Experiment (DOE) and Finite Element Method (FEM). 